\title{
MIELITE TRANSVERSA COMO MANIFESTAÇÃO CLÍNICA INICIAL DE LINFOMA NÃO HODGKIN DISSEMINADO E MIELOPATIA VACUOLAR ASSOCIADA AO HIV
}

\author{
RELATO DE CASO
}

\begin{abstract}
LEANDRO P. DE MOURA* MARCO T.A. SILVESTRE* *, FÁTIMA R.N. ARAÚUO**, MARCIUS K. N. BURGARELLI** AÉRCIO S. BORGES **, FERNANDO A. VINHAL** , ADEMIR ROCHA ${ }^{\star \star * *}$, CESAR N. RAFFIN"****, MARCELO S. FERREIRA ${ }^{\star \star \star \star \star * *}$
\end{abstract}

RESUMO - Linfomas não Hodgkin de alto grau são comumente relatados em pacientes com a síndrome da imunodeficiência adquirida (AIDS). Comprometendo com grande frequência o sistema nervoso central, particularmente as leptomeninges e os hemisférios cerebrais. O acometimento epidural é pouco frequente, variando de $3,5 \%$ a $8,3 \%$ de acordo com os registros da literatura. Os autores relatam o caso de um paciente de 27 anos de idade com AIDS, cuja manifestação clínica inicial da doença linfomatosa disseminada foi a mielite transversa associada à mielopatia vacuolar. Destaca-se a importância do diagnóstico diferencial precoce das mielopatias na AIDS, em virtude da alta malignidade da neoplasia e da evolução extremamente rápida nesses pacientes.

PALAVRAS-CHAVE: mielite transversa, linfoma não Hodgkin, mielopatia vacuolar, AIDS.

Transverse myelitis as initial symptom of disseminated non-Hodgkin lymphoma and HIV-associated vacuolar myelopathy: case report

ABSTRACT - Non-Hodgkin lymphoma is frequently seen in AIDS patients usually affecting the central nervous system (CNS), especially the leptomeninges and the cerebral hemispheres. The epidural involvement is rarely described, ranging from $3.5 \%$ to $8.3 \%$ among the CNS sites. The authors present a case of disseminated non Hodgkin lymphoma associated to vacuolar myelopathy in a 27 years-old male patient with AIDS emphasizing the importance of this differential diagnosis in the myelopathies of AIDS.

KEY WORDS: acute transverse myelitis, non-Hodgkin lymphoma, vacuolar myelopathy, AIDS.

O comprometimento crônico da medula espinhal mais frequente na síndrome da imunodeficiência adquirida (AIDS) é a mielopatia vacuolar, diferentemente registrado entre cerca de 30 e $90 \%$ dos pacientes com acometimento do sistema nervoso pelo HIV (vírus da imunodeficiência humana) ${ }^{13.24}$. Os vacúolos que definem a patologia são caracterizados por alargamento dos espaços interlamelares e periaxonais, que geralmente contêm macrófagos. Topograficamente, as lesões se concentram nos funículos laterais e posteriores da medula espinhal e regionalmente, com maior frequência, no segmento torácico ${ }^{7}$. A correlação entre a presença do HIV e a mielopatia tem sido

Faculdade de Medicina da Universidade Federal de Uberlândia, Minas Gerais: *Neurologista, ${ }^{* *}$ Infectologista, ${ }^{* * *}$ Residente de Clínica Médica, ******Professor Titular de Infectologia, Departamento de Clínica Médica; ****Professor Titular de Anatomia Patológica, Departamento de Patologia; *****Professor Titular de Neurologia - Departamento de Cirurgia. Aceite: 30-janeiro-1996.

Dr. Leandro Pajuaba de Moura - Rua Johen Carneiro 825 - 38400-031 Uberlandia MG - Brasil Fax 0342182246. 
questionada em vários estudos ${ }^{8,21,22,24}$. Macrófagos infectados pelo HIV parecem estar presentes na medula espinhal de todos os pacientes com mielopatia vacuolar, apesar de representarem apenas pequena percentagem do número total de macrófagos e micróglia presentes. Os mecanismos de formação dos vacúolos e do acúmulo dos macrófagos são pouco compreendidos. Tyor et al ${ }^{30}$ propõem que a produção de linfocinas, como o fator de necrose tumoral- $\alpha$, pela micróglia e pelos macrófagos ativados, seria o fenômeno que iniciaria a lesão da mielina ou do oligodendrócito com perda da função neuronal. A lesão tecidual estimularia a micróglia restante e os macrófagos para nova secreçāo de citocinas, que amplificariam a resposta imunológica ${ }^{30}$.

O linfoma não Hodgkin, em pacientes HIV positivos, pode acometer o sistema nervoso central (SNC) como tumor primário ou como metástase de linfoma sistêmico. Uma característica marcante destas neoplasias associadas à AIDS (LNHD-AIDS) é a disseminação extranodal da doença no diagnóstico inicial ( $84 \%$ segundo Levine ${ }^{15}$ e 75 a $95 \%$ segundo Kaplan"). A frequência de envolvimento do SNC varia de $15,4 \%$ a $43 \%$, sendo o linfoma encefálico o achado mais comum ${ }^{12.15 .33}$. O comprometimento epidural varia de $3,5 \%$ a $8,3 \%$ 12.19. Apenas $15 \%$ dos pacientes com este tipo de linfoma foram diagnosticados previamente à síndrome de compressāo espinhal, numa série de pacientes não aidéticos ${ }^{9}$.

Não há relato, em literatura do nosso conhecimento, de casos como o que registramos e em que a manifestação inicial do LNHD-AIDS tenha sido mielopatia transversa associada à mielopatia vacuolar.

\section{RELATO DO CASO}

JFL, masculino, 27 anos, HIV positivo (técnica ensaio imunoenzimático, 2 amostras), homossexual, procurou o Pronto Socorro do Hospital de Clínicas da Universidade Federal de Uberlândia, em 27-outubro1994, com história de lombalgia há cerca de 20 dias, febre de $38,5^{\circ} \mathrm{C}$, parestesias tipo dormência e paraparesia crural progressiva assimétrica, mais intensa à direita, tendo evoluído para paraplegia, retenção urinária e obstipação intestinal. O exame neurológico (9-novembro-1994) mostrou paraplegia flácida nos membros inferiores; reflexos tendinosos abolidos; reflexos cutâneos abdominais, plantar e cremastérico superficial e profundo ausentes; trofismo muscular preservado, sem fasciculações; sensibilidades artrestésica, palestésica, dolorosa, tátil e térmica abolidas até o nivel das regiões mamilares. Evoluiu com aparecimento do sinal de Babinski bilateralmente em 16-novembro-1994.

Exames complementares - O líquido cefalorraqueano (LCR) em 27-outubro-1994 mostrava-se incolor, límpido, com 16 células $/ \mathrm{mm}^{3}$, glicorraquia de $28 \mathrm{mg} / \mathrm{dL}$ (não foi realizada glicemia simultânea), proteinorraquia de $90 \mathrm{mg} / \mathrm{dL}$; Gram e cultura para bactérias negativos; pesquisa direta e cultura para bacilos alcoolácido resistentes e para fungos negativas; reaçōes imunológicas para T. cruzi (imunofluorescência indireta e hemaglutinação passiva), HTLV (ensaio imunoenzimático - Abbott@), cisticercose (ensaio imunoenzimático) e sífilis (VDRL), negativos. Hemaglutinação para toxoplasmose no LCR: IgM negativa e IgG positiva com título de 1/64. Ensaio imunoenzimático (Organon $\odot$ ) no soro para toxoplasmose: IgM negativa e IgG positiva com título maior que $1 /$ 3200. Nova punção lombar (17-novembro-1994) 21 dias após, revelou LCR xantocrômico, com presença de coágulo, 1 leucócito $/ \mathrm{mm}^{3}$ e 453 hemácias $/ \mathrm{mm}^{3}$, glicorraquia de $68 \mathrm{mg} \% / \mathrm{dL}$ (sem glicemia simultânea) e proteinorraquia de $1210 \mathrm{mg} / \mathrm{dL}$. Nảo foi realizada pesquisa de células neoplásicas no LCR. A tomografia computadorizada (TC) da medula torácica foi normal; TC de crânio, normal. Ultrasonografia (USG) de abdome (17. novembro-1994) mostrou hepatomegalia, aumento pancreático e massa sólida de $133 \mathrm{~cm}^{3}$ na fossa ilíaca esquerda.

Evoluçāo - O paciente evoluiu com pneumonia bacteriana e sepse. Óbito em 18-novembro1994 (41 dias após o início da sintomatologia).

O exame anátomo-patológico revelou linfoma não Hodgkin de alto grau (linfoma centroblástico, segundo a classificação de $\mathrm{Kiel}^{14}$, acometendo linfonodos abdominais e mediastinais posteriores, intestino delgado, pâncreas, vesícula biliar, rins, adrenais, ureteres, bexiga, próstata, vesícula seminal esquerda e coração. Havia ainda: invasão do espaço epidural em correspondência com a medula cervical e torácica, bem como infiltração da dura-máter em múltiplos focos (Fig1); mielopatia vacuolar cérvico-torácica acentuada (Fig 2) e necrose coliquativa segmentar recente em medula torácica (Fig 3); leptomeningite linfomatosa encefálica e medular; encefalite discreta (infiltrado mononuclear perivascular, predominantemente linfocitário). Não havia comprometimento esplênico ou dos linfonodos periféricos. 


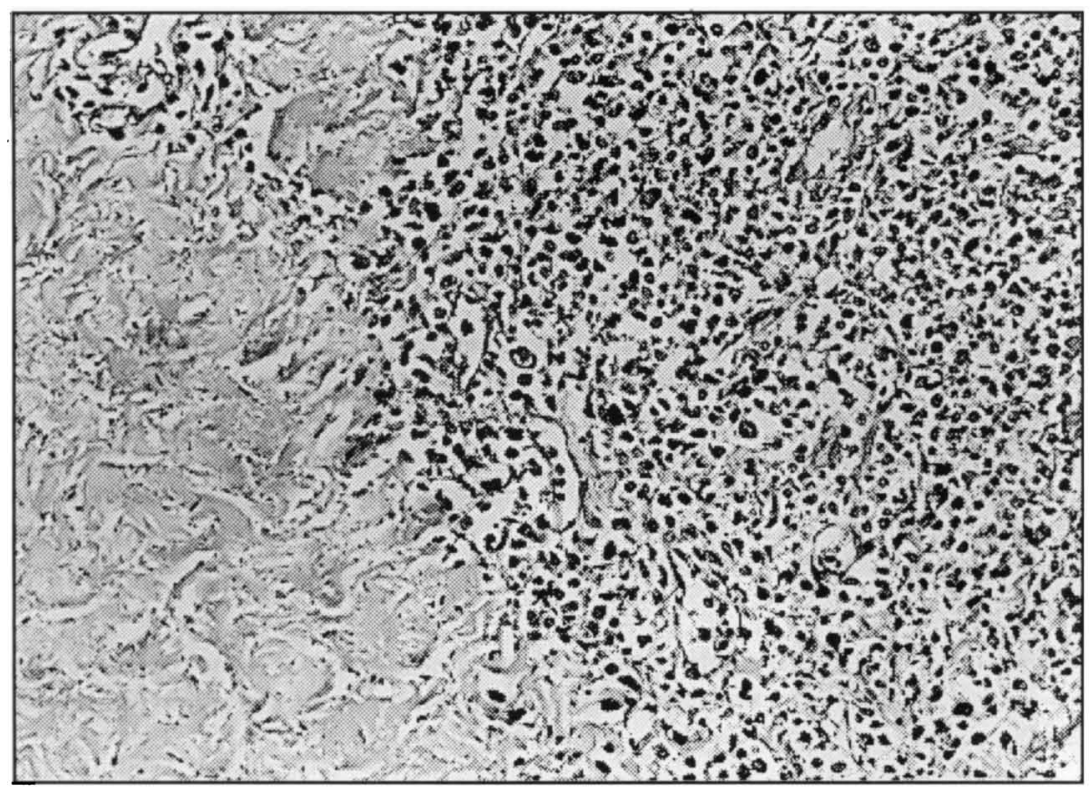

Fig 1. Linfoma infiltrando a dura-mater espinhal. Coloração: luxol-HE. Aumento original: $200 X$.

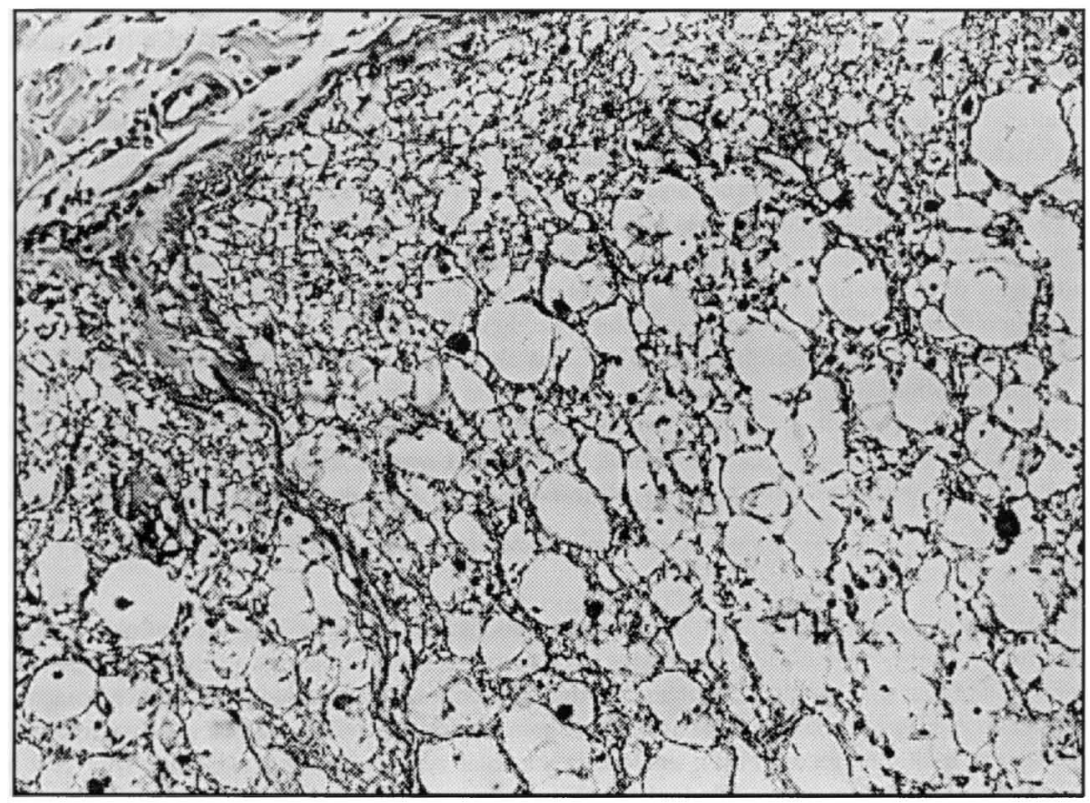




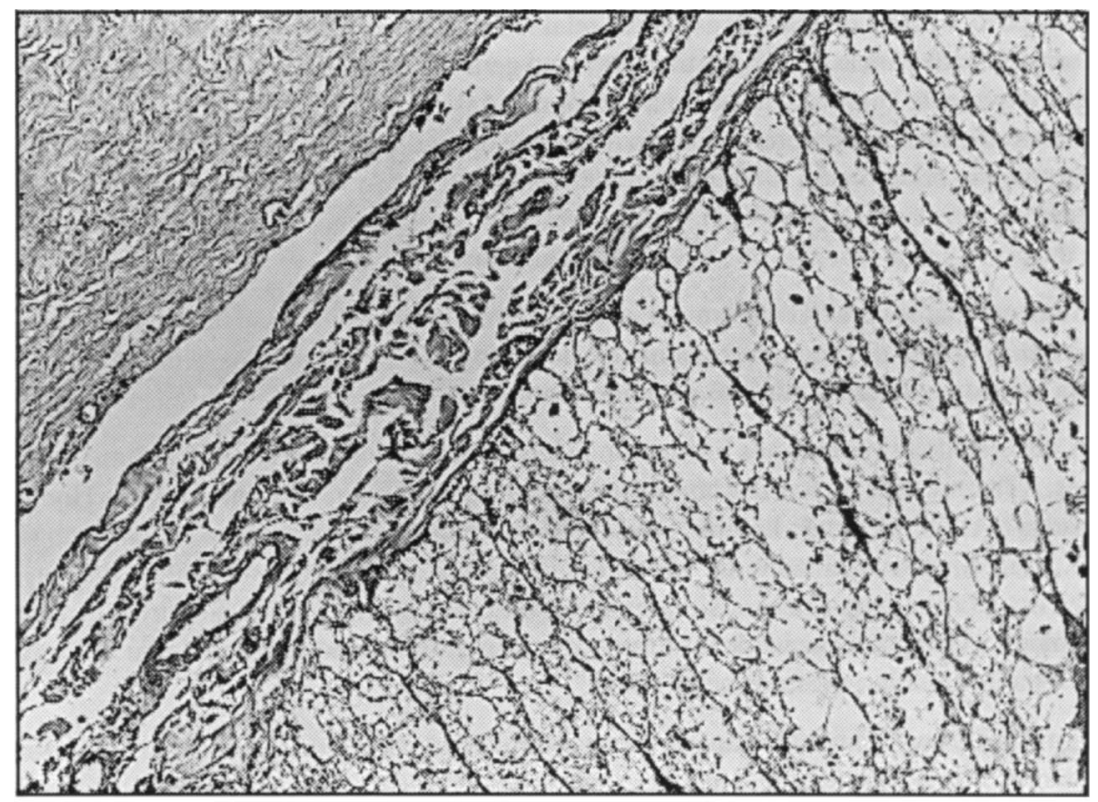

Fig 3. Necrose medular recente. Coloração: luxol-HE. Aumento original: 100X.

\section{DISCUSSÃO}

No presente relato, o diagnóstico topográfico inicialmente foi baseado na anamnese e nos achados de exame neurológico, enfatizando-se a dificuldade deste procedimento nas fases de choque espinhal, durante o qual tais achados podem simular quadros de polirradiculoneuropatia aguda, principalmente na vigência de LCR com dissociação proteíno-citológica, sugestiva de síndrome de Guillain-Barrél. O nível sensitivo bem definido, o comprometimento motor assimétrico e os distúrbios esfincterianos orientaram o diagnóstico sindrômico e topográfico, ratificado na evolução pelo surgimento do sinal de Babinski.

Geralmente, a mielopatia vacuolar tem início insidioso, nas fases de imunossupressão avançada. Nestes casos, o exame neurológico revela paraparesia espástica e hiperreflexia. Existem poucos dados em relação ao estudo do LCR e dos métodos de radiodiagnóstico na mielopatia vacuolar ${ }^{13} \cdot \mathrm{Em}$ raras ocasiões, atrofia espinhal e sinais hiperintensos em $\mathrm{T} 2$ podem ser observados à ressonância nuclear magnética (RNM) ${ }^{3}$. Pode ocorrer necrose do fasciculus gracilis em $14 \%$ dos pacientes ${ }^{21 .}$ Não há tratamento demonstrado atualmente para esta patologia.

A frequência do envolvimento meníngeo no LNHD-AIDS varia de 12 a $17 \% \%^{12,17}$. Apenas 15 de 75 pacientes relatados por Haddad et al ${ }^{9}$ apresentaram aumento da celularidade no LCR, sendo a hiperproteinorraquia detectada em 71 de 77 amostras. Esta dissociação proteíno-citológica, foi evolutivamente confirmada neste relato, tendo provavelmente desenvolvido uma síndrome de Froin. Marcadores de clonogenicidade (como as cadeias kappa e lambda) e a reação em cadeia por polimerase (PCR) podem ser de ajuda para distinguir a proliferação dos linfócitos de uma pleocitose reativa. Cinque et al. ${ }^{4}$ sugerem que a técnica de PCR para a detecção do DNA do vírus de Epstein-Barr pode ser útil como marcador tumoral, relatando sensibilidade de $100 \%$ e especifidade de $98,5 \%$ nos linfomas primários do SNC-AIDS ${ }^{4}$ Tal diagnóstico deve ser prudentemente acompanhado da investigação de outras infeç̧ões que comprometem a medula espinhal ${ }^{25,10.18,20.27 .29,30.32}$. 
O aspecto normal da medula espinhal, relatado à TC, confirma os dados de literatura quanto à baixa sensibilidade para as patologias medulares em geral $^{23.26}$, pois o segmento analisado à tomografia apresentava evidente comprometimento à necrópsia. Assim, a RNM deve ser o método de escolha para os casos suspeitos de comprometimento medular e ou epidural ${ }^{25}$. Haddad et al. ${ }^{9}$ citam 94 pacientes com linfoma não relacionado à AIDS, cuja mielografia foi invariavelmente anormal, podendo tal procedimento, bem como a mielotomografia, substituir parcialmente os métodos não invasivos nas regiões desprovidas de recursos avançados em neuroimagem ${ }^{9.28}$.

Somente diante da USG abdominal, revelando massa sólida na fossa ilíaca esquerda, pôde-se presumir o diagnóstico de tumor, provavelmente de etiologia linfomatosa, pois o linfoma não Hodgkin apresenta elevada incidência entre os pacientes com AIDS.

A duração dos sintomas nos linfomas não Hodgkin relacionados à AIDS raramente excede 2 a 3 meses, refletindo um curso mais homogeneamente agressivo que nos linfomas não Hodgkin não relacionados a AIDS $^{6}$. Segundo Levine ${ }^{16}$, os déficits neurológicos associados ao linfoma não Hodgkin do SNC, resultam provavelmente de vários fatores como: (1) natureza multifocal da doença; (2) infecções associadas, como herpes simplex I e II e herpes zóster, citomegalovírus, tuberculose e toxoplasmose; (3) maior capacidade infiltrativa das células linfomatosas de alto grau; (4) associação com mielopatia vacuolar, presente neste relato.

Em relação ao tratamento, Kaplan " cita que a frequente ocorrência de infecçōes oportunísticas durante o curso da quimioterapia e a pobre reserva hematológica nos pacientes portadores do HIV têm requerido constantes atrasos e reduções nas dosagens medicamentosas, obtendo-se índices de completa resposta em apenas 33 a $57 \%$ dos casos. A abordagem terapêutica vigorosa somente será bem sucedida se realizada precocemente e deve ser considerada nos pacientes com boas condiçōes clínicas. A sobrevida média é de 6.5 meses ${ }^{17}$. Existem relatos de pacientes que apresentaram resposta completa com sobrevida média de 20 meses; em outras séries, $15 \%$ dos pacientes tiveram sobrevida maior que 2 anos $^{12}$ Loureiro et al. ${ }^{19}$ sugerem profilaxia para o SNC nos casos de linfoma sistêmicoAIDS, baseados no índice de $66 \%$ de envolvimento deste sistema demonstrado à autópsia ${ }^{19}$.

Os fatores prognósticos significativamente associados à menor sobrevida são: (1) história de AIDS prévia ao diagnóstico de linfoma; (2) envolvimento de medula óssea; (3) envolvimento extranodal e (4) taxa de linfócitos CD4+ menor que $100 / \mathrm{mm}^{3}$.

A pesquisa de novos quimioterápicos menos tóxicos associados a fatores hematopoéticoestimuladores e terapia anti-retrovírus será fundamental para um tratamento futuro eficaz, com a expectativa de aumento da sobrevida acima da média de 6,5 meses previamente relatada ${ }^{17}$. Para isto, torna-se essencial que o diagnóstico do linfoma não Hodgkin seja afastado nas mielites transversas agudas relacionadas à AIDS, associadas ou não a mielopatias de outras etiologias.

\section{REFERÊNCIAS}

1. Adams RD, Victor M. Diseases of the spinal cord. In Lamsbackwj, Navrosov M (eds). Principles of neurology. Ed5. Singapore: Mg Graw Hill, 1993;1078-1116.

2. Ahmed MD. Survival after herpes simplex type II myelitis. Neurology 1988;38:1500.

3. Berger JR. AIDS and the nervous system. In Aminoff MJ, (ed) Neurology and general medicine. Ed 2. New York: Chruchill Livingstone 1995;757-778.

4. Cinque P, Brytting M, Vago L, Castagna A, Parravicini C, Zanchetta N, Monforte A D, Wahren B, Lazzarin A, Linde A. Epstein-Barr virus DNA in cerebral spinal fluid from patients with AIDS-related primary lymphoma of the central nervous system. Lancet 1993;342:398-401.

5. Clanet M, Rascol A, Rascol M. Les menigites à liquide clair. Encycl Med Cir. Neurologie, 17160 C10, 9Paris: Editions Technique, 1981 .

6. Forsyth PA, Yahalom J, DeAngelis LM. Combined-modality therapy in the treatment of primary central nervous system lymphoma in AIDS. Neurology 1994;44:1473-1479.

7. Goldstick L, Mandybur TI, Bode R. Spinal cord degeneration in AIDS. Neurology 1985;35:103-106. 
8. Gray F, Gherardi R, Trotot P, Fenelon G, Poirier J. Spinal cord lesions in the acquired immune deficiency syndrome (AIDS). Neurosurg Rev 1990;13:189-194.

9. Haddad P, Thaell JF, Kieley JM, Harrison EG Jr, Miller RH. Lymphoma of the spinal extradural space. Cancer 1976;38:1862-1866.

10. Heller HM, Carnevale NT, Steigbigel RT. Varicella zoster virus transverse myelitis without cutaneous rash. Am J Med 1990;88:550-551.

11. Kaplan LD. HIV-associated non-Hodgkin's lymphoma. HIV Adv Res Ther. 1992;2:9-15.

12. Kaplan LD, Abrams DI, Feigal E, McGrath M, Kahn J, Neville P, Ziegler J, Volberding PA. AIDS-associated non-Hodgkin's lymphoma in San Francisco. JAMA 1989;261:719-724.

13. Katlama C. Manifestations neurologiques de l'infeccion à VIH. Encycl Méd Chir, Neurologie, 17-051-B10. Paris: Edition Technique, 1993.

14. Lennert K, Mohri N. Classification of non-Hodgkin's lymphomas. In Handbuch der speziellen pathologischen Anatomie und Histologie: Part B. Malignant lymphomas other non Hodgkin's disease. New York: SpringerVerlag, 1978;101-106.

15. Levine AM. AIDS-related lymphoma: clinical aspects and biology of disease. Adv Oncol 1991;7:18-25.

16. Levine AM. AIDS-associated malignant lymphoma. Med Clin N Am. 1992;76:253-268.

17. Levine AM, Wernz JC, Kaplan L, Rodman N, Cohen P, Mtroka C, Bennett JM, Rarick MU, Walsh C, Kahn J, Miles S, Ehmann WC, Feinberg J, Nathwani B, Gill PS, Mitsuyasu R. Low-dose chemotherapy with central nervous system prophylaxis and zidovudine maintenance in AIDS-related lymphoma: a prospective multi-institucional trial. JAMA 1991;266:84-88.

18. Livramento JA, Machado LR, Spina-França A. Anormalidades do líquido cefalorraqueano em 170 casos de AIDS. Arq Neuropsiquiatr 1989;47:326-331.

19. Loureiro C, Gill PS, Meyer PR, Rhodes R, Rarick MU, Levine AM. Autopsy findings in AIDS-related lymphoma. Cancer 1988; 62:735-739.

20. Olson EM, Wong WHM, Hesselink JR. Extraspinal abnormalities detected on MRI of the spine. AJR 1994;162:679-684.

21. Petito CK, Vechio D, Chen YT. HIV antigen and DNA in AIDS spinal cords correlate with macrophage infiltration but not with vacuolar myelopathy. J Neuropathol Exp Neurol 1994;53:86-94.

22. Rhodes RH, Ward JM, Cowan RP, Moore PT. Immunohistochemical localization of human immumnodeficiency viral antigens in formalin-fixed spinal cords with AIDS myelopathy. Clin Neuropathol 1989;8:22-27.

23. Roland J, Braun M, Moret C, Blanchet B, Anxionnat R, Bracard S, Picard L. Imagerie médullorachidienne: scanographie et IRM. Encycl Méd Chir, Neurologie, 17-035-A-60. Paris: Editions Techniques, 1992.

24. Rosenblum M, Scheck AC, Cronin K, Brew BJ, Khan A, Paul M, Price RW. Dissociation of AIDS-related vacuolar myelopathy and productive HIV-1 infection of the spinal cord. Neurology 1989;39:892-896.

25. Sharif HS. Role of MR imaging in the management of spinal infections. AJR, 1992;158:1333-1345.

26. Sze G. MR Imaging of the spinal cord: current status and future advances. AJR 1992:159:149-159.

27. Tekkök IH, Berker M, Özcan OE, Özgen T, Alkalin E. Brucellosis of the spine. Neurosurgery 1993;33:838-844.

28. Townsend RR. CT of AIDS-related lymphoma. AJR 1991;156:969-974.

29. Tucker T, Dix RD, Katzen C. Cytomegalovirus and herpes simplex virus ascending myelitis in a patient with acquired immune deficiency syndrome. Ann Neurol 1985;18:74-79.

30. Tyor WR, Glass JD, Baumrind N, McArthur JC, Griffin JW, Becker PS, Griffin DE. Cytokine expression of macrophages in HIV-1-associated vacuolar myelopathy. Neurology 1993;43:1002-1009.

31. Wiley CA, van Patten MD, Carpenter PM, Pwell HC, Thal LJ. Acute ascending necrotizing myelopathy caused by herpes simplex virus type II. Neurology 1987;37:1791-1794.

32. Woolsey RM, Chambers TJ, Chung HD, McGarry JD. Mycobacterial meningomyelitis associated with human immunodeficiency virus infection. Arch Neurol 1988;45:691-693.

33. Ziegler JL, Beckstead JA, Volberding PA, Abrams DI, Levine AM, Lukes RJ, Gill PS, Burkes RL, Meyer PR, Metroka GE, Mouradian J, Moore A, Riggs SA, Butler JJ, Cabanillas FC, Hersh E, Newell GR, Laubenstein LJ, Knowles D, Odajnyk C, Raphael B, Koziner B, Urmacher C, Clarkson BD. Non-Hodgkin's lymphoma in 90 homosexual men. N Engl J Med 1984;311:565-570. 